\section{SAT0543 QUALITY OF LIFE IN BEHÇET'S SYNDROME: THE ROLE OF PATIENT REPORTED OUTCOME}

R. Talarico, A. d'Ascanio, R. Neri, C. Tani, C. Baldini, M. Mosca. Department of Clinical and Experimental Medicine, University of Pisa, Rheumatology Unit, Pisa Italy

Background: Behçet's syndrome (BS) is a systemic vasculitis, typically characterised by recurrent oro-genital ulcers, ocular inflammation and skin manifestations; articular, vascular, gastro-enteric and neurological involvement may also occur.The complex pattern of BS profile can effect negatively on patients' quality of life.

Objectives: The primary aim of this study was to explore the role of quality of life in $\mathrm{BD}$ patients by means of patient reported outcome (PRO); the secondary aim was to study any correlation between disease activity and quality of life.

Methods: The study enrolled 130 patients $(71 \mathrm{M}, 59 \mathrm{~F})$, all fulfilling the International Study Group (ISG) criteria for BS. Their mean age was $42 \pm 8$ years, 18-77 while the mean age at disease onset was $11 \pm 4$ years $5-18$ and the mean followup of $8 \pm 2$ years. Disease activity was evaluated by means of the Behçet's Disease Current Activity Form (BDCAF), while Short-form-36 (SF-36) was used to evaluate quality of life. Disease activity was compared with the global SF-36 score and with each dimension, that includes: physical functioning, physical disability, body pain, general health, vitality, social functioning, emotional disability, menta health. The statistical analysis was performed using Student t-test, Mann-Whitney-U test, ANOVA and Pearson correlation

Results: At time of evaluation, according BDCAF, 51 BS patients (39\%) had clinically active disease (36 muco-cutaneous involvement, 21 ocular involvement 10 joint involvement, 6 neurological involvement, 4 gastro-enteric). As expected, the overall SF-36 scores were significantly lower in patients with clinically active disease. Moreover, female BS patients had statistically significant lower scores in all SF-36 domains compared with male patients. When each domain of SF-36 was evaluated, we found that physical disability $(\mathrm{p}=0.004)$, body pain $(\mathrm{p}=0.006)$, general health $(p=0.001)$, and vitality $(p=0.001)$ were significantly lower in patients with disease activity. Notably, vitality $(p=0.001)$, physical disability $(p=0.004)$, social functioning $(p=0.001)$, emotional disability $(p=0.003)$ and mental health $(p=0.001)$ were significantly lower in patients with muco-cutaneous active disease, compared with the other patients with active disease.

Conclusions: The clinicians who take care of any chronic disease would like to correctly know the current status of a patient to manage him properly. In this regard, the combination data of PRO measures and disease activity have been demonstrated to add more information compared to the evaluation of disease activity alone. These consideration suggest that the correct assessment of BS needs a multi-dimensional approach, that fairly includes disease activity, disease damage and quality of life

Disclosure of Interest: None declared

DOI: 10.1136/annrheumdis-2018-eular.7078

\section{\begin{tabular}{l|l} 
SAT0544 & COMPARING THE CLINICAL PROFILE OF ADULTS AND
\end{tabular} CHILDREN WITH BEHÇET'S SYNDROME IN THE UK}

S. Myers ${ }^{1}$, E. Makmur ${ }^{1}$, L. Hanns ${ }^{1}$, D. Huskard ${ }^{2}$, P. Brogan ${ }^{1}$, N. Ambrose ${ }^{1}$

${ }^{1}$ University College London; ${ }^{2}$ Imperial College London, London, UK

Background: Behçet's syndrome (BS) is a rare multi-system inflammatory disorder and most commonly presents in young adults. Clinical phenotypic variance across geographical regions is recognised but there has been no UK publication assessing UK BS patients' variance by age groups. BS is primarily a clinical diagnosis, and there is significant diagnostic delay in the UK. Exploration of the phenotype in UK adults and children may help clinicians diagnose BS more effectively.

Objectives: Describe and compare the clinical features of adults and children with BS in a UK population.

Methods: We examined and compared two cumulative databases of clinical features of BS patients. The paediatric database was collected Great Ormond Street Hospital for Children, London $(n=46)$. The adult database was collected at the Hammersmith Hospital, London $(n=560)$.

Results: Oral ulcers were common for both paediatric $(97.8 \%)$ and adult $(96.6 \%)$ populations. Genital ulceration also did not differ between paediatric $(73.9 \%)$ and adult $(75.7 \%)$ groups. Eye involvement was rare in children $(4.3 \%)$ versus adults $(37 \%)(p<0.001)$. Skin involvement was more common in the adult cohort $(55.4 \%$ vs. $21.7 \%, p<0.001)$. There was a trend towards increased vascular involvement in adults (17.5\%) versus children (6.5\%). The children had higher gastrointestinal involvement compared to adults ( $21.7 \%$ vs. $4.5 \%, p<0.001)$

Conclusions: Paediatric BS patients displayed less ocular and skin manifestations compared to the adult BS patients. The BS UK phenotype differs from international cohorts. This information will be valuable in helping clinicians diagnose BS in UK adult and paediatric populations.

Disclosure of Interest: None declared

DOI: 10.1136/annrheumdis-2018-eular.1638

\section{SAT0545 \\ GIANT CELL ARTERITIS AND HEMATOLOGIC MALIGNANCIES: A REAL-LIFE EXPERIENCE}

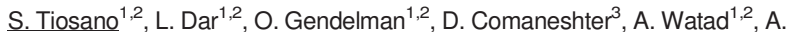
D. Cohen ${ }^{3,4}$, H. Amital ${ }^{1,2}$. IInternal Medicine 'B', Sheba Medical Center, TelHashomer, Ramat-Gan; ${ }^{2}$ Sackler School of Medicine, Tel-Aviv University; ${ }^{3}$ Chief Physician's office, Clalit Health Services, Tel-Aviv, ${ }^{4}$ Siaal Research Center for Family Medicine and Primary Care, Faculty of Health Sciences, Ben-Gurion University of the Negev, Beer-Sheva, Israel

Background: Giant cell arteritis (GCA), also known as temporal arteritis, is a vasculitis of large and medium-sized vessels, which commonly involves the extracranial branches of the carotid artery. There are conflicting evidence regarding the association between GCA and both solid and hematologic malignancies. ${ }^{1-4}$

Objectives: To assess the coexistence rate of GCA and hematologic malignancies.

Methods: This cross-sectional study was performed utilising the database of Israel's largest healthcare association, Clalit Health Services (CHS). All patients with previously documented diagnosis of GCA were included, as well as age-and sex matched controls without GCA. The proportions of Hodgkin's lymphoma, NonHodgkin's lymphoma and multiple myeloma were compared between patients and controls. Univariate analysis was compared using chi-square test for categorical variables and student's t-test for continuous variables. A multivariable logistic regression model was built to assess the covariates associated with each NonHodgkin's lymphoma, the hematologic malignancy with the highest number of patients.

Results: The study included 5,663 GCA patients and 28308 controls with a mean age of 71 and 68.3 , respectively. Both groups consisted of $69.8 \%$ females. Multiple myeloma was observed in 27 GCA patients $(0.48 \%)$ and 53 controls $(0.19 \%)$, crude $\mathrm{OR}=2.56 \mathrm{p}<0.001$. Hodgkin's lymphoma was observed in $19 \mathrm{GCA}$ patients $(0.34 \%)$ and 41 controls $(0.14 \%)$, crude $O R=2.33 p=0.004$. Non-Hodg kin's lymphoma was observed in 64 GCA patients $(1.13 \%)$ and 164 controls $(0.58 \%)$, crude $\mathrm{OR}=1.96 p<0.001$. Multivariable logistic regression model adjusting for age and gender found GCA as independently associated with Non-Hodgkin's lymphoma (adjusted OR 1.96, $p<0.001$ ).

\begin{tabular}{|c|c|c|c|c|}
\hline Characteristic & $\begin{array}{l}\text { No GCA } \\
n=28308\end{array}$ & GCA $n=5663$ & OR & p.ratio \\
\hline$\overline{\text { Age }}$ & $68.3 \pm 27.4$ & $71.0 \pm 15.6$ & $\begin{array}{c}1.00 \\
{[1.00 ; 1.00]}\end{array}$ & $<0.001$ \\
\hline Gender: Female & $19767(69.8 \%)$ & $\begin{array}{c}3954 \\
(69.8 \%)\end{array}$ & $\begin{array}{c}1.00 \\
{[0.94 ; 1.06]}\end{array}$ & 0.991 \\
\hline BMI & $28.2 \pm 5.91$ & $28.1 \pm 5.60$ & $\begin{array}{c}1.00 \\
{[0.99 ; 1.00]}\end{array}$ & 0.081 \\
\hline \multicolumn{5}{|l|}{ Socioeconomic status: } \\
\hline Low & 5443 (36.8\%) & $\begin{array}{c}1970 \\
(34.9 \%)\end{array}$ & Ref. & Ref. \\
\hline Medium & 6241 (42.2\%) & $\begin{array}{c}2339 \\
(41.4 \%)\end{array}$ & $\begin{array}{c}1.04 \\
{[0.97 ; 1.11]}\end{array}$ & 0.330 \\
\hline High & 3093 (20.9\%) & $\begin{array}{c}1336 \\
(23.7 \%)\end{array}$ & $\begin{array}{c}1.19 \\
{[1.10 ; 1.30]}\end{array}$ & $<0.001$ \\
\hline Multiple Myeloma & $53(0.19 \%)$ & $27(0.48 \%)$ & $\begin{array}{c}2.56 \\
{[1.59 ; 4.04]}\end{array}$ & $<0.001$ \\
\hline Hodgkin's Lymphoma & $41(0.14 \%)$ & $19(0.34 \%)$ & $\begin{array}{c}2.33 \\
{[1.32 ; 3.97]}\end{array}$ & 0.004 \\
\hline $\begin{array}{l}\text { Non-Hodgkin's } \\
\text { Lymphoma }\end{array}$ & $164(0.58 \%)$ & $64(1.13 \%)$ & $\begin{array}{c}1.96 \\
{[1.46 ; 2.61]}\end{array}$ & $<0.001$ \\
\hline
\end{tabular}

Conclusions: GCA patients have higher rate of hematologic malignancies compared to controls. The association with Non-Hodgkin's lymphoma is the most prominent, and proper screening methods should be applied for early detection and treatment.

\section{REFERENCES}

[1] Askling J. Do steroids increase lymphoma risk? A case-control study of lymphoma risk in polymyalgia rheumatica/giant cell arteritis. Ann Rheum Dis 64:1765-1768. doi:10.1136/ard.2005.036459

[2] Liozon E, Loustaud V, Fauchais A-L, et al. Concurrent temporal (giant cell) arteritis and malignancy: report of 20 patients with review of the literature. J Rheumatol 2006;33:1606-1614.

[3] Kermani TA, Schäfer VS, Crowson CS, et al. Malignancy risk in patients with giant cell arteritis: A population-based cohort study. Arthritis Care Res NA-NA. doi:10.1002/acr.20062

[4] Solans-Laque R, Bosch-Gil JA, Pérez-Bocanegra C, et al. Paraneoplastic vasculitis in patients with solid tumors: report of 15 cases. J Rheumatol 35:294-304.

Disclosure of Interest: None declared DOI: 10.1136/annrheumdis-2018-eular.4886 